\title{
Morality in Intergroup Conflict
}

\author{
Nir Halevy ${ }^{1}$, Tamar A. Kreps ${ }^{1}$, Ori Weisel ${ }^{2}$ and Amit Goldenberg ${ }^{1}$ \\ ${ }^{1}$ Stanford University \\ ${ }^{2}$ University of Nottingham
}

\section{$\underline{\text { Contact information }}$}

Nir Halevy*

655 Knight Way

Graduate School of Business

Stanford University

Stanford, CA, 94305

Phone: 1-650-723-8525

Email: nhalevy@stanford.edu

*corresponding author

Tamar A. Kreps

655 Knight Way

Graduate School of Business

Stanford University

Stanford, CA, 94305

Email: tkreps@stanford.edu
Ori Weisel

Centre for Decision Research and

Experimental Economics

Sir Clive Granger Building, Room C34

University of Nottingham, University Park

Nottingham, NG7 4DA, UK

Phone: 0044-9515458

Email: ori.weisel@nottingham.ac.uk

Amit Goldenberg

Jordan Hall, Building 420

Department of Psychology

Stanford University

Stanford, CA, 94305

Phone: 1-415-299-9492

Email: amitgold@stanford.edu 
Morality in Intergroup Conflict 2

\title{
Morality in Intergroup Conflict
}

\begin{abstract}
Intergroup conflict encompasses a broad range of situations with moral relevance. Researchers at the intersection of social and moral psychology employ diverse methodologies, including surveys, moral dilemmas, economic games, and neuroimaging, to study how individuals think, feel, and act in intergroup moral encounters. We review recent research pertaining to four types of intergroup moral encounters: (a) value-expressive and identity-expressive endorsements of conflict-related actions and policies; (b) helping and harming in-group and out-group members; (c) reacting to transgressions committed by in-group or out-group members; and (d) reacting to the suffering of in-group or out-group members. Overall, we explain how sacred values, social motives, group-based moral emotions, and the physiological processes underlying them, shape moral behavior in intergroup conflict.
\end{abstract}


December 16, 2014: As we are writing this article, CNN reports that Taliban militants slaughtered more than 140 children and their teachers in Peshawar, Pakistan. Terrorism, war, and genocide pervade the lives of millions of people throughout the world, spreading suffering and destruction. What motivates individuals to fight, kill, and die on behalf of groups? How do sacred values, moral emotions, and their underlying physiology, shape intergroup conflict? In recent years, scientists at the intersection of social and moral psychology have begun to provide answers to these theoretically and practically important questions.

Intergroup conflict encompasses a broad range of situations with moral relevance. The current review is organized around four types of moral encounters embedded in the context of intergroup conflict: (a) value-expressive and identity-expressive endorsements of conflictrelated actions and policies; (b) helping and harming in-group and out-group members; (c) reacting to transgressions committed by in-group or out-group members; and (d) reacting to the suffering of in-group or out-group members. Addressing these four types of moral encounters, we discuss how sacred values, social motives, moral emotions, and the physiological processes underlying them, shape moral behavior in intergroup conflict.

Researchers use a diverse set of methodologies to study these distinct types of moral encounters. Research on value-expressive endorsements of actions and policies often surveys members of natural groups engaged in violent real-world conflict. Research on identityexpressive moral behavior typically elicits responses to hypothetical moral dilemmas. Research on helping and harming in-group and out-group members usually establishes ad-hoc experimental groups and employs economic games in which group members choose how to allocate their resources. Finally, research on reactions to transgressions by in-group or outgroup members, as well as the suffering of in-group or out-group members, often uses self- 
report measures of emotional experiences alongside neuroimaging techniques. Our brief review cuts across these diverse methodologies.

\section{Value-Expressive and Identity-Expressive Endorsements of Actions and Policies}

Sacred values operate as moral imperatives that delineate which conflict-related actions and policies are right versus wrong, which, in turn, constrain and direct individual support for these actions and policies [1]. For example, individuals' support of war depends on their perceptions of the righteousness of armed violence, rather than the strategic efficacy of warfare [2]. In addition, people react with moral outrage when offered payment for self-sacrificial behavior during intergroup conflict, or when asked to consider tradeoffs between sacred and non-sacred issues in intergroup negotiation [3]. The power of sacred values is not lost on savvy groups, whose leaders use sacred values to motivate group members' self-sacrificial behavior and win public support for their cause [4]. Indeed, most suicide attacks are committed by insurgent organizations that use religious values and political messages in tandem to increase popular support [5].

Self-sacrifice has also been conceptualized as identity-expressive behavior. Individuals report willingness to self-sacrifice to save fellow group members when their fear of death is mitigated by strong feelings of embeddedness in the group [6,7]. For example, fused individuals - those whose personal identity completely overlaps with their group identityexpress greater willingness to self-sacrifice for fellow in-group members in classic trolley dilemmas. This willingness generalizes to members of extended in-groups, but not to out-group members [8]. When facing information about threat to fellow in-group members, strongly fused individuals experience negative emotions as if they themselves were under threat, and intuitively and swiftly express willingness to protect the group [9]. Linking the value-expressive 
and identity-expressive accounts of self-sacrificial behavior, research shows that encouraging fused individuals to believe that members of their group share certain core characteristics, such as genes or values, leads them to perceive familial ties with fellow in-group members, which, in turn, triggers a sense of duty to self-sacrifice to protect group members from harm [10].

\section{Helping and Harming "Us" and "Them"}

When group members participate in intergroup conflict, they invest time and effort, and risk injury or death on behalf of their group. Individuals can direct these costly contributions toward helping fellow in-group members, harming out-group members, or both. They can also direct their contributions toward helping out-group members. Research using economic games has found that, faced with a choice to help in-group members either with or without harming out-group members, most individuals prefer to help in-group members without harming outgroup members [11]. In addition, helping in-group members without harming out-group members is rewarded with higher social status than helping in-group members while also harming out-group members [12]. Interestingly, groups reward parochial helping more than universal helping: Individuals who help fellow in-group members are conferred higher status than those who use their resources to help both in-group and out-group members [13]. Despite the robust preference for "in-group love" over "out-group hate", certain aggravating conditions spur harm to out-groups. For example, interactions with morality-based out-groups, such as the members of a fascist political party, have been shown to increase resource allocations aimed at harming out-group members [14].

Recent research documented the influence of hormones on intergroup behavior, with a particular focus on oxytocin, a hormone best known for its role in childbirth and social bonding. For example, compared with individuals receiving placebo, individuals receiving oxytocin (self- 
administered using intranasal spray) allocate more resources to benefit fellow in-group members and protect their in-group, but show no difference in resource allocation aimed at harming out-group members [15]. In a similar vein, individuals administered oxytocin show greater intergroup bias [16], an effect driven primarily by a heightened concern for and cooperation with in-group members, rather than antagonism for and competition against outgroup members [17]. Oxytocin has also been shown to increase group-serving-but not selfserving - unethical behavior, such as cheating [18].

The effects of oxytocin on intergroup behavior depend on the intergroup context. In highly cooperative intergroup contexts, individuals who received oxytocin were more likely to benefit both in-group and out-group members [19]. In contrast, in highly competitive intergroup contexts, individuals who received oxytocin preferred to form an alliance with threatening ingroup members, who were seen as capable of harming others and hence as useful allies in intergroup conflict, rather than with non-threatening in-group members [20].

\section{Reactions to Transgressions by "Us" and "Them"}

Moral group-based emotions arise when group or intergroup events activate individuals' perceptions of right or wrong. Transgressions committed in the context of intergroup conflict often trigger group-based anger and guilt $[21,22]$. Individuals experience group-based anger in reaction to goal blocking and perceived injustice $[23,24]$. In turn, group-based anger prompts various action tendencies, which can be either destructive (consistent with anger's negative valence) or constructive (consistent with anger's approach orientation) [23]. Individuals who experience group-based anger show stronger support for retaliation [25], but also report greater willingness to engage in risky, non-aggressive political negotiations [22] and elicit stronger empathic responses from out-group members [26]. Evidence suggests that anger becomes 
destructive in the presence of other negative, avoidance-oriented emotions such as group-based hatred [23] or group-based contempt [26,27].

Individuals experience group-based guilt when they perceive that their group is responsible for a moral transgression. Guilt is intensified when group members believe that their group should and can make amends to restore justice. Taking responsibility for a moral transgression is potentially threatening to one's collective identity. One way to attenuate this threat is by self-affirming aspects of one's identity that are unrelated to the threatened aspect. Indeed, research in Israel and Bosnia found that self-affirmation increased individuals' willingness to acknowledge in-group responsibility for moral transgressions, their feelings of group-based guilt, and support for reparation policies [28]. In addition to increasing support for reparation [29], group-based guilt also increases people's willingness to make symbolic gestures, such as apologizing for wrongdoing [30].

Group-based hope can increase individuals' support for actions aimed at resolving seemingly intractable intergroup conflict. Individuals experience group-based hope when they believe that their group's current situation is malleable and will change for the better [31]. Perceptions of malleability negatively predict aggression and positively predict support for education over punishment $[32,33]$. Group-based hope in the context of the Israeli-Palestinian conflict positively predicted individuals' willingness to make concessions [32] and their acquisition of information in favor of conflict resolution [34]. Group-based hope also increases support for humanitarian aid, even during times of war [35], and facilitates intergroup forgiveness [36].

Reactions to the Suffering of In-group and Out-group Members 
People show less empathy toward the suffering of out-group members as compared with in-group members, in part because they dehumanize out-group members [37]. Given people's social desirability concerns and reticence to self-report these thoughts and feelings, researchers have utilized implicit measures — neural, hormonal, and physiological — that are indicative of people's emotional reactions to the suffering of in-group and out-group members [38]. For example, people who see needles pricking in-group members' hands, but not out-group members', experience a sensorimotor pain response. Response to the pain of uncategorized targets is weaker than to in-group pain but stronger than (the non-existent response) to outgroup pain [39]. People who show this intergroup empathy gap are also less willing to help and more willing to harm out-group members. For instance, individuals show deficits in empathy, and even schadenfreude (taking pleasure in others' pain), toward rivals of groups with which they identify but to which they do not belong; these schadenfreude responses, in turn, prompt intentions to aggress against these targets [40].

This intergroup empathy gap is a complex phenomenon moderated by social and cultural contexts, and thus changes from one intergroup context to the next [41]. The bias is stronger among individuals who strongly endorse social hierarchy (e.g., Koreans vs. Caucasian Americans [42]); belong to low-status groups; or strongly identify with their group [43]. It also depends on stereotype content: Envied targets (i.e., low warmth, high competence) elicit more bias (i.e., less sympathy) than disgusting targets (i.e. low warmth, low competence) or pitied targets (i.e. high warmth, low competence) [44,45].

Consistent with the moderating role of socio-cultural contexts, fMRI studies show that the intergroup empathy gap is associated with brain areas implicated in cognition, rather than the more affective "pain matrix" (i.e., the anterior cingulate cortex and insula). Whereas 
empathy for an uncategorized target activates the pain matrix, the difference in activation in response to the suffering of an in-group member versus an out-group member is observed in cognitive areas, including the medial prefrontal cortex [43] and left temporo-parietal junction [42]. Thus, in-group-bounded empathy may have distinct psychological underpinnings that differ from the affective processes underlying generalized empathy.

Neuropsychological methods have also illuminated how intergroup contexts weaken the activation of people's individual moral standards. For example, when people process moral stimuli in a group context, they show reduced activation in social-cognitive brain areas associated with self-reflection [46]. The same people who show these lower levels of activation, in turn, subsequently engage in more intergroup antisocial behavior, suggesting that losing touch with one's own moral standards facilitates intergroup aggression.

\section{Conclusion}

To understand and predict individual moral behavior in intergroup conflict, we need to understand the interplay between people's social motives, identities and emotions, as well as the underlying neural and hormonal processes that drive them. We have reviewed research on each of these determinants; considering how they interact with each other would enhance our understanding of human behavior in moral encounters embedded within intergroup conflict. 


\section{References}

1. Atran S, Ginges J: Religious and sacred imperatives in human conflict. Science 2012, 336:855857.

2. Ginges J, Atran S: War as a moral imperative (not just practical politics by other means). Proc. R. Soc. Lond. B Biol. Sci. 2011, 278:2930-2938.

3. Ginges J, Atran S, Sachdeva S, Medin D: Psychology out of the laboratory: the challenge of violent extremism. Am. Psychol. 2011, 66:507.

4. Sheikh H, Ginges J, Coman A, Atran S: Religion, group threat and sacred values. Judgm. Decis. Mak. 2012, 7:110-118.

5. Ginges J, Hansen I, Norenzayan A: Religion and support for suicide attacks. Psychol. Sci. 2009, 20:224-230.

6. Orehek E, Sasota JA, Kruglanski AW, Dechesne M, Ridgeway L: Interdependent self-construals mitigate the fear of death and augment the willingness to become a martyr. J. Pers. Soc. Psychol. 2014, 107:265-275.

7. Swann Jr WB, Gómez Á, Huici C, Morales J, Hixon JG: Identity fusion and self-sacrifice: arousal as a catalyst of pro-group fighting, dying, and helping behavior. J. Pers. Soc. Psychol. 2010, 99:824.

8. Swann WB, Gómez Á, Dovidio JF, Hart S, Jetten J: Dying and killing for one's group identity fusion moderates responses to intergroup versions of the trolley problem. Psychol. Sci. 2010, 21:1176-1183.

9. Swann Jr WB, Gómez Á, Buhrmester MD, López-Rodríguez L, Jiménez J, Vázquez A: Contemplating the ultimate sacrifice: Identity fusion channels pro-group affect, cognition, and moral decision making. J. Pers. Soc. Psychol. 2014, 106:713.

* 10. Swann Jr WB, Buhrmester MD, Gómez A, Jetten J, Bastian B, Vázquez A, Ariyanto A, Besta T, Christ O, Cui L, et al.: What makes a group worth dying for? Identity fusion fosters perception of familial ties, promoting self-sacrifice. J. Pers. Soc. Psychol. 2014, 106:912. 
This paper identified perceptions of family-like connections with fellow citizens as a central mechanism that carries the effect of identity-fusion to self-sacrificial behavior on behalf of group members.

11. Halevy N, Weisel O, Bornstein G: "In-group love" and "out-group hate" in repeated interaction between groups. J. Behav. Decis. Mak. 2012, 25:188-195.

* 12. Halevy N, Chou EY, Cohen TR, Livingston RW: Status conferral in intergroup social dilemmas: behavioral antecedents and consequences of prestige and dominance. J. Pers. Soc. Psychol. 2012, 102:351.

This paper shows that individuals who made costly contributions that helped in-group members were conferred higher status, were protected against exclusion from the group, and received more leadership votes than individuals who either withheld resources or harmed out-group members. In contrast, selfishness and aggressiveness fueled perceptions of dominance.

* 13. De Dreu CK, Balliet D, Halevy N: Parochial Cooperation in Humans: Forms and Functions of Self-Sacrifice in Intergroup Conflict. Adv. Motiv. Sci. 2014, 1:1-47.

This paper reviews social, motivational and biological determinants of self-sacrificial behavior in intergroup conflict.

14. Weisel O, Böhm R: Ingroup love and outgroup hate in intergroup conflict between natural groups. Manuscr. Submitt. Publ. 2015, [no volume].

15. De Dreu CKW, Greer LL, Handgraaf MJJ, Shalvi S, Van Kleef GA, Baas M, Ten Velden FS, Van Dijk E, Feith SWW: The neuropeptide oxytocin regulates parochial altruism in intergroup conflict among humans. Science 2010, 328:1408-1411.

16. De Dreu CKW, Greer LL, Van Kleef GA, Shalvi S, Handgraaf MJ: Oxytocin promotes human ethnocentrism. Proc. Natl. Acad. Sci. 2011, 108:1262-1266.

17. Van IJzendoorn MH, Bakermans-Kranenburg MJ: A sniff of trust: meta-analysis of the effects of intranasal oxytocin administration on face recognition, trust to in-group, and trust to out-group. Psychoneuroendocrinology 2012, 37:438-443.

* 18. Shalvi S, De Dreu CKW: Oxytocin promotes group-serving dishonesty. Proc. Natl. Acad. Sci. 2014, 111:5503-5507. 
In a double-blind, placebo-controlled experiment, participants receiving nasally-administered oxytocin lied more when lying served their group-but not when it was only self-serving-as compared to receiving placebo.

* 19. Israel S, Weisel O, Ebstein RP, Bornstein G: Oxytocin, but not vasopressin, increases both parochial and universal altruism. Psychoneuroendocrinology 2012, 37:1341-1344.

A double-blind, placebo-controlled experiment examining behavior in a nested social dilemma showed that oxytocin - but not argenine-vasopressin-increases the willingness to make costly contributions to both local public goods (benefitting in-group members) and global public goods (benefitting in-group and out-group members).

20. De Dreu CKW, Shalvi S, Greer LL, Van Kleef GA, Handgraaf MJ: Oxytocin motivates noncooperation in intergroup conflict to protect vulnerable in-group members. PloS One 2012, 7:e46751.

21. Van Zomeren M, Leach CW, Spears R: Protesters as "Passionate Economists" A Dynamic Dual Pathway Model of Approach Coping With Collective Disadvantage. Personal. Soc. Psychol. Rev. 2012, 16:180-199.

22. Reifen Tagar M, Federico CM, Halperin E: The positive effect of negative emotions in protracted conflict: The case of anger. J. Exp. Soc. Psychol. 2011, 47:157-164.

23. Halperin E, Russell AG, Dweck CS, Gross JJ: Anger, hatred, and the quest for peace: Anger can be constructive in the absence of hatred. J. Confl. Resolut. 2011, 55:274-291.

24. Halperin E, Gross JJ: Intergroup anger in intractable conflict: Long-term sentiments predict anger responses during the Gaza war. Group Process. Intergroup Relat. 2011, 14:477-488.

25. Cheung-Blunden V, Blunden B: The emotional construal of war: Anger, fear, and other negative emotions. Peace Confl. 2008, 14:123-150.

26. De Vos B, van Zomeren M, Gordijn EH, Postmes T: The communication of "pure" groupbased anger reduces tendencies toward intergroup conflict because it increases out-group empathy. Pers. Soc. Psychol. Bull. 2013, 39:1043-1052.

17. Hutcherson CA, Gross JJ: The moral emotions: A social-functionalist account of anger, disgust, and contempt. J. Pers. Soc. Psychol. 2011, 100:719. 
28. Gunn GR, Wilson AE: Acknowledging the skeletons in our closet: the effect of group affirmation on collective guilt, collective shame, and reparatory attitudes. Pers. Soc. Psychol. Bull. 2011, [no volume].

* 29. Goldenberg A, Saguy T, Halperin E: How group-based emotions are shaped by collective emotions: Evidence for emotional transfer and emotional burden. J. Pers. Soc. Psychol. 2014, 107:581.

This paper expands the classical notion of emotional influence by examining cases in which group members emotionally compensate for inappropriate collective emotional response. These findings shed light on the role of emotions in societal change.

30. Čehajić-Clancy S, Effron DA, Halperin E, Liberman V, Ross LD: Affirmation, acknowledgment of in-group responsibility, group-based guilt, and support for reparative measures. J. Pers. Soc. Psychol. 2011, 101:256.

31. Cohen-Chen S, Halperin E, Saguy T, van Zomeren M: Beliefs About the Malleability of Immoral Groups Facilitate Collective Action. Soc. Psychol. Personal. Sci. 2013, [no volume].

* 32. Cohen-Chen S, Halperin E, Crisp RJ, Gross JJ: Hope in the Middle East Malleability Beliefs, Hope, and the Willingness to Compromise for Peace. Soc. Psychol. Personal. Sci. 2014, 5:67-75.

This paper addresses one of the biggest challenges in intractable conflicts, which is the despair that group members experience regarding the prospects of resolving the conflict. The authors show that perceptions of group malleability are an important factor in leading group members to experience hope in conflicts and strive for reconciliation.

33. Yeager DS, Miu AS, Powers J, Dweck CS: Implicit Theories of Personality and Attributions of Hostile Intent: A Meta-Analysis, an Experiment, and a Longitudinal Intervention. Child Dev. 2013, 84:1651-1667.

34. Cohen-Chen S, Halperin E, Porat R, Bar-Tal D: The Differential Effects of Hope and Fear on Information Processing in Intractable Conflict. J. Soc. Polit. Psychol. 2014, 2:11-30.

35. Halperin E, Gross JJ: Emotion regulation in violent conflict: Reappraisal, hope, and support for humanitarian aid to the opponent in wartime. Cogn. Emot. 2011, 25:1228-1236. 
36. Greenaway KH, Cichocka A, Veelen R, Likki T, Branscombe NR: Feeling hopeful inspires support for social change. Polit. Psychol. 2014, [no volume].

37. Buckels EE, Trapnell PD: Disgust facilitates outgroup dehumanization. Group Process. Intergroup Relat. 2013, [no volume].

38. Cikara M, Bruneau EG, Saxe RR: Us and them intergroup failures of empathy. Curr. Dir. Psychol. Sci. 2011, 20:149-153.

39. Avenanti A, Sirigu A, Aglioti SM: Racial bias reduces empathic sensorimotor resonance with other-race pain. Curr. Biol. 2010, 20:1018-1022.

40. Cikara M, Botvinick MM, Fiske ST: Us versus them social identity shapes neural responses to intergroup competition and harm. Psychol. Sci. 2011, 22:306-313.

* 41. Cikara M, Van Bavel JJ: The Neuroscience of Intergroup Relations: An Integrative Review. Perspect. Psychol. Sci. 2014, 9:245-274.

Further in-depth review of literature on the neuroscience of intergroup relations.

42. Cheon BK, Im D, Harada T, Kim J-S, Mathur VA, Scimeca JM, Parrish TB, Park HW, Chiao JY: Cultural influences on neural basis of intergroup empathy. Neuroimage 2011, 57:642-650.

43. Mathur VA, Harada T, Lipke T, Chiao JY: Neural basis of extraordinary empathy and altruistic motivation. Neuroimage 2010, 51:1468-1475.

44. Cikara M, Fiske ST: Bounded empathy: Neural responses to outgroup targets'(mis) fortunes. J. Cogn. Neurosci. 2011, 23:3791-3803.

* 45. Cikara M, Fiske ST: Stereotypes and schadenfreude: Affective and physiological markers of pleasure at outgroup misfortunes. Soc. Psychol. Personal. Sci. 2012, 3:63-71.

This paper, based on the Stereotype Content Model, argues that people's empathy for outgroups depends on those outgroups' perceived warmth and competence. Participants reported feeling least bad, and smiled more (as measured by EMG zygomaticus major response), when bad events befell envied - high competence, low warmth - targets, as compared to other types of outgroups; however, when these envied outgroups were made to seem higher in warmth, lower in competence, or both, they no longer elicited as much schadenfreude. 
46. Cikara M, Jenkins A, Dufour N, Saxe R: Reduced self-referential neural response during intergroup competition predicts competitor harm. NeuroImage 2014, 96:36-43. 